\title{
Riemann Hypothesis Clay Institute Millennium Problem Solution
}

\section{Cusack P*}

Independent Researcher, Canada

*Corresponding author: Cusack P, Independent Researcher, Canada, Tel: (506)214-3313; E-mail: st-michael@hotmail.com

Received date: July 05, 2016; Accepted date: July 27, 2016; Published date: August 02, 2016

Copyright: (C) 2016 Cusack P. This is an open-access article distributed under the terms of the Creative Commons Attribution License, which permits unrestricted use, distribution, and reproduction in any medium, provided the original author and source are credited.

\begin{abstract}
This paper explains how the Riemann Hypothesis is a critical line which results from the Golden Mean Parabola skewed at 60 degrees. The equation gives the roots to the serial of Prime Numbers. The 6-0 degree failure Plane comes from soil physics.
\end{abstract}

Keywords: Hypothesis; Capacity; Mechanics; Soil physics

\section{Problem}

The Riemann zeta capacity $\zeta(\mathrm{s})$ is a capacity whose contention $s$ might be any perplexing number other than 1 , and whose qualities are additionally unpredictable. It has zeros at the negative even numbers; that is, $\zeta(s)=0$ when $s$ is one of $-2,-4,-6$. These are called its insignificant zeros. Be that as it may, the negative even whole numbers are by all account not the only values for which the zeta capacity is zero. Alternate ones are called non-unimportant zeros. The Riemann speculation is worried with the areas of these non-trifling zeros, and states that:

The genuine part of each non-minor zero of the Riemann zeta capacity is $1 / 2$.

In this way, if the speculation is right, all the non-minor zeros lay on the basic line comprising of the mind boggling numbers $1 / 2+i t$, where $t$ is a real number and it is the fanciful unit (Figure 1) [1].

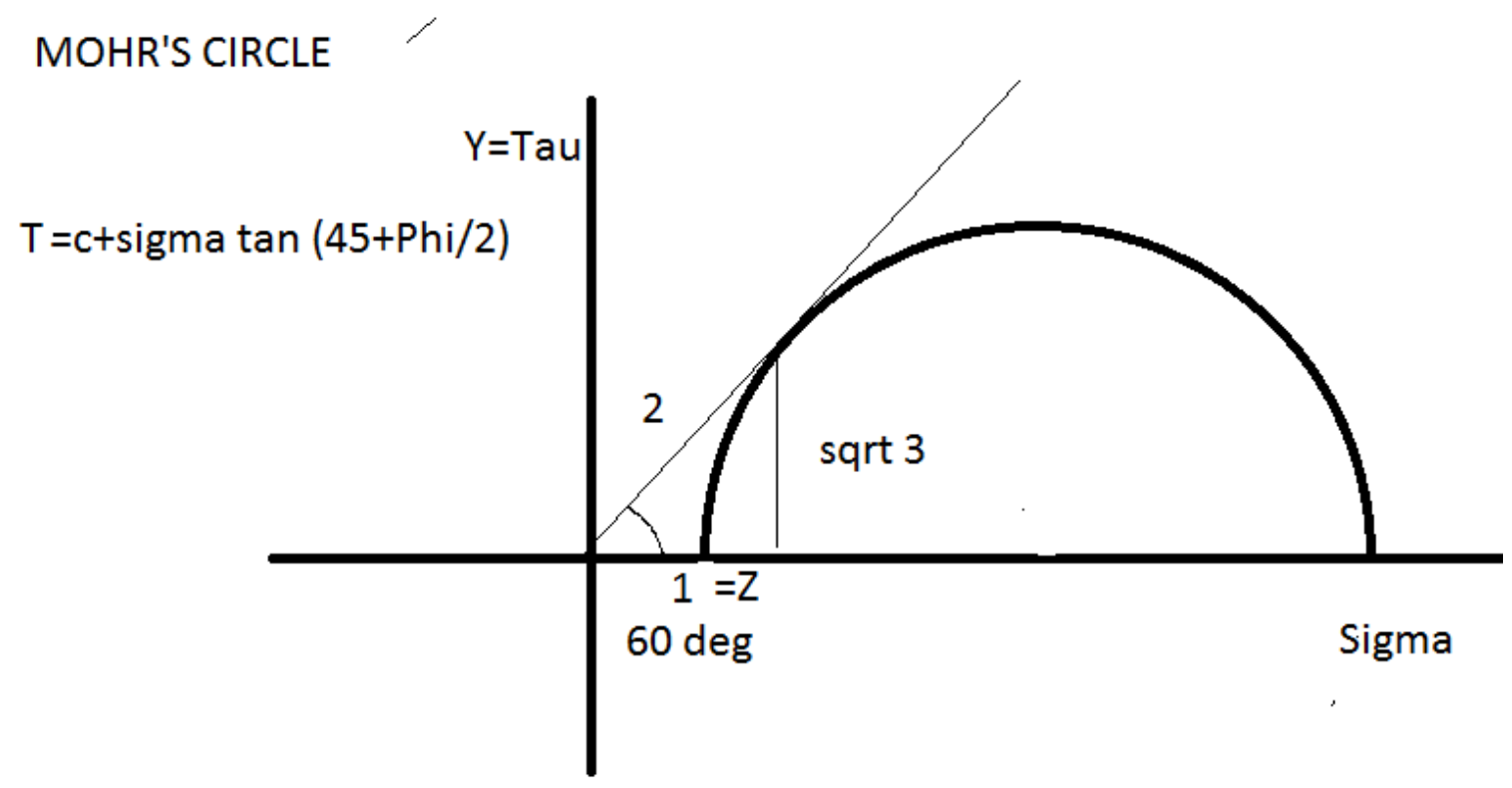

Figure 1: Illustration 1 Mohr's circle.

\section{Soil Mechanics}

From soil mechanics we know from Mohr-Coulomb Failure:

$\mathrm{Tau}=\mathrm{c}+\operatorname{sigma}^{\star} \tan (45+\mathrm{Phi} / 2)$

$26.667=0+\left(\right.$ sqrt $3^{*} \tan (45+30 / 2)=26.667 /$ sqrt $3 h=0.1539$
$(\mathrm{F}=26.667$ is the shear failure pressure. Refer to Astrotheology Cusack's Model of the Universe)

$\mathrm{Tau}=\mathrm{F}=\sin$ theta $=88.5=\mathrm{k}=$ Permeability of the Universe [2].

So,

$\mathrm{Au} / 2=\sin 60$ degrees 
Citation: Cusack P (2016) Riemann Hypothesis Clay Institute Millennium Problem Solution. J Appl Computat Math 5: 317 . doi:

$\left.\mathrm{Z}^{\wedge} 2+(\operatorname{sqrt} 3)^{\wedge} 2\right] / 2=\sin 60$

$\mathrm{Z}=0.5774=1 / \mathrm{sqrt} 3=\tan 30$ degrees

$\mathrm{Y}=\operatorname{tau}=1 / \tan 30$ degrees $=\cot 30$ degrees $=$ sqrt $3=\tan 60$

$\mathrm{y} / \mathrm{z}=$ rise $/ \mathrm{run}=\mathrm{m}$ in the Y-z PLANE

$\operatorname{Tan} 60=\mathrm{Y} / \mathrm{z}=3.4641 / 10=\mathrm{e}^{\wedge} \mathrm{Z}$

$\mathrm{Y}=\mathrm{e}^{\wedge} \mathrm{Z}$

This is the critical line of the Riemann Hypothesis (Figures 2 and 3).

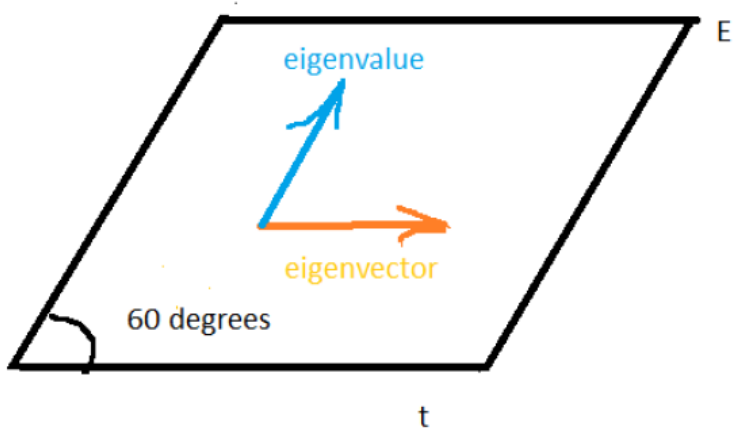

Figure 2: Illustration skewed energy time plane.

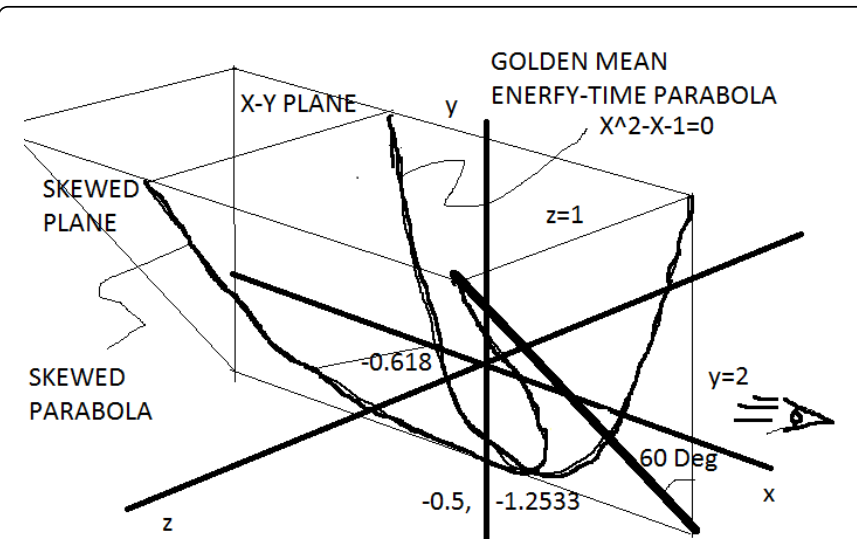

Figure 3: Illustration golden mean skewed parabola.

Equation of a Plane

$a x+b y+c z=0$,

Equation of golden mean parabola,

$\mathrm{X}^{\wedge} 2-\mathrm{x}-1=0$,

Setting these equal to the skewed plane and the Energy-Time Parabola:

$A x+b y=\sin 60^{\star} z=x^{\wedge} 2-x-1$,

There are 5 unknowns; therefore 5 coincident points are necessary. They are:

\section{Golden mean roots}

$\mathrm{X}=1.618, \mathrm{Y}=0, \mathrm{Z}=0$ (Point 1 ),
$\mathrm{X}=-0, .618, \mathrm{Y}=0, \mathrm{Z}=0$ (Point 2),

Minimum point of parabola

$\mathrm{X}=0.5, \mathrm{Y}=-1.2533, \mathrm{Z}=0$ (Point 3),

X-Y Plane,

$\mathrm{X}=1, \mathrm{Y}=\mathrm{O}, \mathrm{Z}=0$ (Point 4 ).

\section{Critical Line}

The Critical Line of the Riemann Hypothesis is as viewed as a straight line, whose equation is of course

$\mathrm{Y}=\mathrm{mz}+\mathrm{b}$. However, in a Physical sense, the straight line is at a 60degree skew. That means we are actually viewing the universe as Energy skewed ay 60 degrees. The true, unaltered universe is the $\mathrm{z}$ axis.

To us inside the universe, this phenomenon is undetectable. We live in it, move and have our being. Author theorizes that the universe unskewed lies "outrode" our present perception of a 60 degree skewing. So, the equation of the straight line is as viewing the skewed plane in which the Energy time parabola lies [3].

$\mathrm{Y}=\mathrm{mz}+\mathrm{b}$,

$2,0,1$

$0=m(1)+b$,

$\mathrm{B}=-\mathrm{m}$,

Rise over run $=m=2 /-1=-2$,

$\mathrm{Y}=2-2 \mathrm{Z}$

$\mathrm{X}=2, \mathrm{Y}=0, \mathrm{Z}=1$ (Point 5).

\section{Solve system of 5 equations; 5 unknowns}

$A=-1$,

$\mathrm{B}=-0.4892 \sim-0.5$,

$\mathrm{Z}=\mathrm{sqrt} 2$,

$\mathrm{Y}=-0.8154$,

$\mathrm{X}=0.9087$,

- $\mathrm{Y}=2-2 \mathrm{z}$

- $\mathrm{A}(1)+\mathrm{b}(0)+\sin 60$ degrees $(0)=1^{\wedge} 2-1-1$,

- $\mathrm{A}=-1$,

- $\mathrm{A}(1 / 2)+\mathrm{b}(-1.2533)+\sin 60(0)=(1 / 2)^{\wedge} 2-1 / 2-1$,

- $\mathrm{B}=0.4892 \sim-1 / 2$,

- $\mathrm{Ax}+\mathrm{by}+\sin 60 \mathrm{z}=1.618^{\wedge} 2-1.618-1$,

- $0.8666 z-0.4892 y=1.618$,

and

$\mathrm{Y}=2-2 \mathrm{Z}$

$\mathrm{Y}=2-2$ (sqrt 2),

$\mathrm{Y}=-0.8154$,

$0.866 \mathrm{z}(0.4892(2-2 \mathrm{z})=1.618$,

$\mathrm{Z}=$ sqrt 2 ,

(5) Ax+by+sin 60(z) $=x^{\wedge} 2-x-1$, 
$-\mathrm{x}+\mathrm{by}+\sin 60 \mathrm{z}=\mathrm{x}^{\wedge} 2-\mathrm{x}-1$,

$(-1 / 2)(0.8154)+0.866($ sqrt 2$)=x^{\wedge} 2$,

$\mathrm{X}=0.0987$.

\section{Critical line}

$m=-2 / 1=-2$,

$\mathrm{Y}=\mathrm{mx}+\mathrm{b}$

$\mathrm{Y}=2-2 \mathrm{z}$,

$\mathrm{Y}=2-2(1 / 2)$,

$\mathrm{y}=1$,

$\mathrm{Y}^{\prime}=-2$,

$y-y^{\prime}-2 z$,

$y=y^{\prime}-2(1 / 2)$,

$\mathrm{yy}^{\prime}=-1$,

$x=0, y=1, z=1 / 2$,

$\mathrm{E}=\mathrm{E}^{\prime}-\mathrm{E}$,

$E^{\prime}=2 E$,

$\mathrm{E}=\mathrm{E}^{\prime} / 2$,

$\mathrm{Y}=1 / 2 \mathrm{y}^{\prime}$,

$\mathrm{Y}=\mathrm{y}$,

$\mathrm{Y}=\mathrm{e}^{\wedge} \mathrm{z}$,

$\mathrm{Y}=\mathrm{y}^{\prime}\left(2 \mathrm{e}^{\wedge} \mathrm{z}\right)$,

$\mathrm{Y}=\mathrm{y}^{\prime}+\mathrm{C} 1$,

$\mathrm{Y}=\mathrm{e}^{\wedge} \mathrm{Z}$,

$\mathrm{Y}=\mathrm{e}^{\wedge} \mathrm{Z}$

$\mathrm{E}^{\wedge} 1=\mathrm{e}^{\wedge}(-1)+\mathrm{C} 1$,

$\mathrm{C} 1=0.23504$.

Number system based on 10 :

$\operatorname{Ln} \mathrm{C} 1)=3.157 \sim \mathrm{Pi}$,

$\mathrm{Y}=\mathrm{e}^{\wedge} \mathrm{Z}+\mathrm{Ln}(\mathrm{Pi})$,

$\mathrm{Y}=\mathrm{e}^{\wedge} \mathrm{Z}+\mathrm{Pi}$

This is the critical line of prime numbers. The only true numbers are prime numbers, The regular number line is a skewed version of the prime numbers: $1,2,3,4,5,6,7,8,9, \ldots$ etc.

Let Energy=time; or $Y=z$. The universe exists because of the tension between the unalterable 1 and $\mathrm{Pi}$. If we let $\mathrm{Pi}=1$ in our new equation, we get,

$\mathrm{Z}=\mathrm{e}^{\wedge} \mathrm{z}+1$,

$\mathrm{Z}-\mathrm{e}^{\wedge} \mathrm{Z}=1$,

$\operatorname{Ln}(\mathrm{z})^{\star} \mathrm{z}=1$,

Ln $z=1 / z$.

$\mathrm{Y}=\mathrm{y}^{\prime}$ (as usual, the derivative equals the function. It does too for this Riemann Hypothesis) [3].

\section{Prime Numbers Calculated from Equation}

$$
\begin{aligned}
& Y=e^{\wedge} \mathrm{Z}+\mathrm{Pi}, \\
& Y^{\prime}=\mathrm{e}^{\wedge} \mathrm{Z}, \\
& Y=\mathrm{y}^{\prime}=\mathrm{m}=-2, \\
& \mathrm{X}^{\wedge} 2-\mathrm{x}-1=0, \\
& (-2)-2(-2)-1=5 \text { Prime, } \\
& \mathrm{Z}^{\wedge} 2-\mathrm{z}-1=-3, \\
& Z=1,-3 \text { (Prime), } \\
& Z^{\wedge} 2-\mathrm{z}-1=-7, \\
& Z=-2,3, \\
& Z^{\wedge} 2-\mathrm{z}-1=-11, \\
& Z=,-4,3 \text { etc. }
\end{aligned}
$$

This then is the critical line of the solution to the prime numbers according to the Riemann hypothesis [2].

Imaginary Number Equal to Conjugate of the Golden Mean Now,

$1 / 2+\mathrm{it}$

$1 / 2+($ sqrt -1$) z$,

Golden mean equation,

$\mathrm{X}=1 /[\mathrm{X}-1]$,

$1+\mathrm{i}=1 /[1+\mathrm{i}]$,

$\mathrm{X}=1 /[\mathrm{x}-1]$,

$(1+\mathrm{i})=1 /[1+\mathrm{i})-1$,

$(1+\mathrm{i})=1 / \mathrm{I}$,

$(1+\mathrm{i})^{*} \mathrm{i}=1$,

$\mathrm{I}^{\wedge} 2-\mathrm{i}-1=0$,

Roots (Golden Mean and the Conjugate of the Golden Mean),

$1.618,--0.618$,

$\mathrm{I}=\operatorname{sqrt}(-1)=-0.618$,

The unimaginary number is equal to -0.618 ,

$1 / 2+(-0.618)$ (sqrt 2),

$=0.374=1 / \sin 60$ degrees,

$(1 / \mathrm{m})+\mathrm{i}^{\star} 1 / \sin 60$ degrees $)=1 / 2+\mathrm{it}$.

\section{The Universe}

The Universe exists where the only real numbers $=\mathrm{s}$ are Prime Numbers (Figure 4). Since,

$\mathrm{Y}=\mathrm{y}$ for our universe,

and

$\mathrm{y}=\mathrm{y}^{\prime}=\mathrm{e}^{\wedge} \mathrm{x}$, 
Citation: Cusack P (2016) Riemann Hypothesis Clay Institute Millennium Problem Solution. J Appl Computat Math 5: 317 . doi: 10.4172/2168-9679.1000317

Page 4 of 4

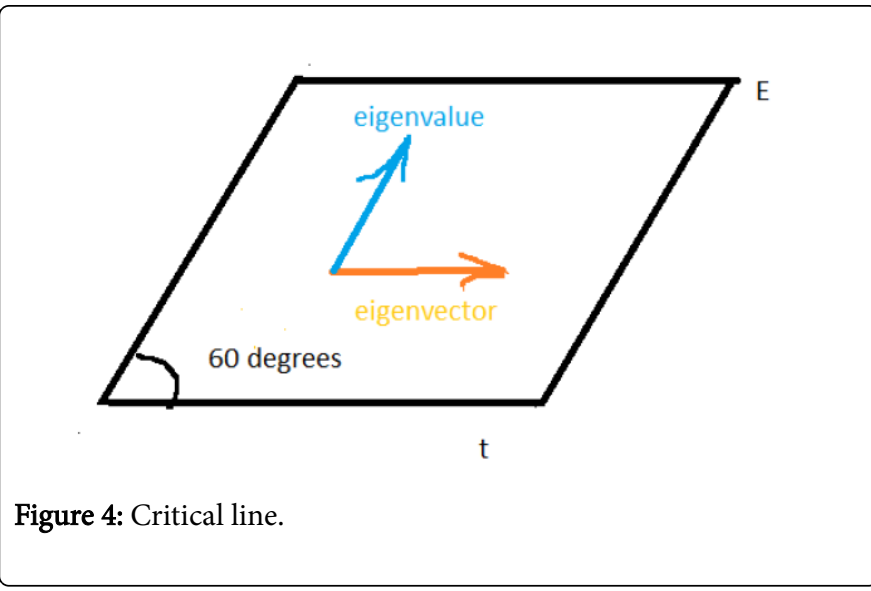

\section{Critical line}

$\mathrm{Y}=\mathrm{mz}+\mathrm{b}$,

$\mathrm{Y}=\mathrm{e}^{\wedge} \mathrm{Z}+\mathrm{Pi}$, $\left(\mathrm{e}^{\wedge} \mathrm{z}+\mathrm{Pi}\right) / \mathrm{e}^{\wedge} \mathrm{z}$

$1+\mathrm{e}^{\wedge} \mathrm{z} / \mathrm{Pi}$,

All Physical Quantities should be divided as such.

$1+\mathrm{e}^{\wedge}(4 / 3) / \mathrm{Pi}=6.93$,

$1 / 6.93=0.1442$,

$1-0.1442=0.855$,

$\operatorname{Sin}(-1)(0.855)=58.84$ degrees $=1.027$ rads $=$ t.

\section{Conclusion}

The critical line for the Riemann Hypothesis is $\mathrm{y}=\mathrm{e}^{\wedge} \mathrm{z}+\mathrm{Pi}$.

\section{References}

1. Smith GN (2006) Elements of Soil Mechanics. Blackwell Publishing.

2. Cusack P (2016) Astrotheology. Blogger P Cusack.

3. Cusack P (2016) Astro-Theology Cusack's Universe. Journal of Physical Mathematics. 